\title{
Adsorptive Removal of Anionic Azo Dye New Coccine Using Silica and Silica-gel with Surface Modification by Polycation
}

\author{
Tien Duc Pham ${ }^{1, *(\infty)}$, Viet Phuong Bui ${ }^{1}$, Thuy Nga Pham ${ }^{1}$, Thi Mai Dung Le ${ }^{2}$, Kim Thuy Nguyen ${ }^{3}$, \\ Van Hoi Bui ${ }^{4}\left(\mathbb{D}\right.$ and The Dung Nguyen ${ }^{1, *}$ \\ 1 Faculty of Chemistry, University of Science, Vietnam National University—Hanoi, 19 Le Thanh Tong, \\ Hoan Kiem, Hanoi 100000, Vietnam; buivietphuong_t63@hus.edu.vn (V.P.B.); \\ phamthuynga_sdh@hus.edu.vn (T.N.P.) \\ 2 Faculty of Environmental Sciences, University of Science, Vietnam National University-Hanoi, \\ 334 Nguyen Trai, Thanh Xuan, Hanoi 100000, Vietnam; lethimaidung_t63@hus.edu.vn \\ 3 Vietnam-Russia Tropical Centre, 63 Nguyen Van Huyen, Cau Giay, Hanoi 100000, Vietnam; \\ nguyenkimthuy@vrtc.org.vn \\ 4 Vietnam Academy of Science and Technology, University of Science and Technology of Hanoi (USTH), \\ 18 Hoang Quoc Viet, Cau Giay, Hanoi 100000, Vietnam; bui-van.hoi@usth.edu.vn \\ * Correspondence: tienduchphn@gmail.com or tienducpham@hus.edu.vn (T.D.P.); \\ nguyentd@hus.edu.vn (T.D.N.)
}

check for updates

Citation: Pham, T.D.; Bui, V.P.; Pham, T.N.; Le, T.M.D.; Nguyen, K.T.; Bui, V.H.; Nguyen, T.D. Adsorptive Removal of Anionic Azo Dye New Coccine Using Silica and Silica-gel with Surface Modification by Polycation. Polymers 2021, 13, 1536. https://doi.org/10.3390/ polym13101536

Academic Editor: Antonio Zuorro

Received: 28 March 2021

Accepted: 8 May 2021

Published: 11 May 2021

Publisher's Note: MDPI stays neutral with regard to jurisdictional claims in published maps and institutional affiliations.

Copyright: (c) 2021 by the authors. Licensee MDPI, Basel, Switzerland. This article is an open access article distributed under the terms and conditions of the Creative Commons Attribution (CC BY) license (https:// creativecommons.org/licenses/by/ $4.0 /)$

\begin{abstract}
In the present work, adsorption of anionic azo dye, new coccine (NCC) on silica and silicagel in an aquatic environment was discovered. Effective conditions such as adsorption time, $\mathrm{pH}$, the influence of dosage on NCC adsorption using strong polycation, poly-diallyl-dimethylammonium chloride (PDADMAC) modified silica (PMS) and PDADMAC modified silica-gel (PMSG) were systematically studied. The removal of NCC using PMS and PMSG were much higher than that using raw silica and silica-gel without PDADMAC in all $\mathrm{pH}$ ranges from 3 to 10. The adsorption of NCC onto PMS and PMSG was achieved maxima at the same conditions of contact time $30 \mathrm{~min}, \mathrm{pH} 6$. The optimum adsorbent dosages of PMS and PMSG for NCC removal were 10 and $20 \mathrm{mg} \cdot \mathrm{mL}^{-1}$ respectively. Experimental results of NCC adsorption isotherms onto PMS and PMSG at different ionic strength were fitted by Langmuir and Freundlich models. The NCC removal efficiencies using PMS and PMSG were higher than 87\%, indicating that PMS and PMSG are novel and reusable adsorbents for removal of anionic dye. Based on adsorption isotherms, and surface group changes after PDADMAC modification and NCC adsorption examined by Fourier transform infrared spectroscopy (FTIR), we demonstrate that electrostatic interaction between positively charged adsorbents' surfaces and negative sulfonic groups of NCC are the main driving force for anionic azo dye adsorption onto PMS and PMGS adsorbents.
\end{abstract}

Keywords: new coccine; adsorption; silica; silica-gel; PDADMAC

\section{Introduction}

Dyes are important chemicals for many industrial activities related to textiles, paper, cosmetics, paint, etc.. However, dye residue is a kind of pollutant for the aquatic environment [1], because many dyes are highly toxic with low biodegradation [2]. Different techniques have been investigated and further developed for treatment to remove dyes from aqueous solution [3,4], such as photocatalysis [5-7], advanced oxidation [8,9], flocculation and coagulation [10], biological processes [11], and adsorption [12-15]. For developing countries, adsorption is one of the most suitable and effective methods for dye removal when using low-cost adsorbents such as minerals, clays or agricultural subproducts [2,16,17]. Various hybridized materials have been investigated for removal of dye through adsorption techniques, such as nanofibrous membrane [18] or porous $\mathrm{g}-\mathrm{C}_{3} \mathrm{~N}_{4}$ nanosheet [19]. In order to produce novel adsorbents, materials can be modified by surface coating [20] or pre-adsorption with active chemical agents [21]. 
Polyelectrolyte is a charged polymer in which monomer molecules contain positively or negatively charged groups [22,23]. A polycation is a polyelectrolyte with positive charge while a polyanion has a negative charge. Recent studies demonstrate that the adsorptive removal of ionic dyes in water environment is significantly enhanced when using surfactants or polyelectrolytes $[2,24]$. For these systems, an understanding of adsorption characteristics and mechanisms of dyes on modified adsorbents with chemical interactions are important to control and increase the removal efficiencies of organic contaminants.

Silica is the dehydrated form of silica-gel material at high temperature. Non-porous and low charge density silica and silica-gel are difficult to remove from ionic dyes directly [25-27]. In this case, surface modifications of silica and silica-gel are required to enhance removal efficiency of ionic dyes. Poly-diallyl-dimethylammonium chloride (PDADMAC) is a strong commercial polycation with $\mathrm{pH}$ independent charging behavior. PDADMAC modifies the solid surface or creates high performance adsorbents for removing some organic pollutants [28-30]. The adsorption of PDADMAC onto silica at different ionic strengths has also been also thoroughly investigated [31]. Nevertheless, to the best of our knowledge, the removal of anionic dye using PDADMAC modified silica and silica-gel materials has not been studied.

Synthetic azo dyes are widely used in numerous industrial activities [13,32]. Adsorption of azo dye on different systems and dye degradation have been thoroughly investigated [33-36]. However, studies on the removal of multivalent azo dyes such as new coccine (NCC) using a novel adsorbent are still inadequate. Wang et al. [37] investigated the removal of NCC using sludge particulates at different $\mathrm{pH}$, suspended solid, and salt concentration. However, this group did not study the impact of the surface modification using polyelectrolyte, and adsorption isotherms were not investigated [37].

This work aims to investigate of the adsorption characteristics of NCC onto silica and silica-gel particles with surface coating by PDADMAC. The change in surface functional group of silica and silica-gel with PDADAMC before and after NCC adsorption is evaluated by Fourier transform infrared spectroscopy (FTIR). We also use different isothermal models to fit adsorption of NCC onto PDADMAC modified silica and silica-gel to suggest adsorption mechanisms.

\section{Materials and Methods}

\subsection{Materials}

High purity silica-gel with a diameter of about $50 \mu \mathrm{m}$ was calcinated at $800{ }^{\circ} \mathrm{C}$ to form silica. The XRD patterns used for confirmation of phase structures of silica-gel and silica particles were conducted by an X-ray diffractometer (Bruker D8 Advance) with $\mathrm{Cu} \mathrm{K} \alpha$ radiation $(\lambda=1.541862 \AA)$. The diffraction intensity was recorded between the range of $2-80^{\circ}(2 \theta)$ with a step increment of $0.02^{\circ}$. Figure 1 shows that both silica and silica-gel have amorphous silicon oxide with specific boarding peaks at 2 theta of $20-26^{\circ}$ [38]. The adsorption and desorption isotherms of $\mathrm{N}_{2}$ to calculate specific surface area according to Brunauer-Emmett-Teller (BET) theory were also conducted. The specific surface area of silica and silica-gel materials were carried out using a surface area analyzer (Nova touch 4LX, Anton Paar). Samples with a weight of about $0.12 \mathrm{~g}$ were measured at $77 \mathrm{~K}$ with liquefied $\mathrm{N}_{2}$ for $9 \mathrm{~h}$. The specific surface areas of 159.6 and $169.7 \mathrm{~m}^{2} / \mathrm{g}$ were found to be for silica and silica-gel, respectively. Energy Dispersive X-ray Spectroscopy (EDX) which is used for elemental analysis of materials was conducted using Oxford Instruments. The EDX shows a high purity of silica and silica-gel with a total amount of Si and O greater than $99 \%$. 


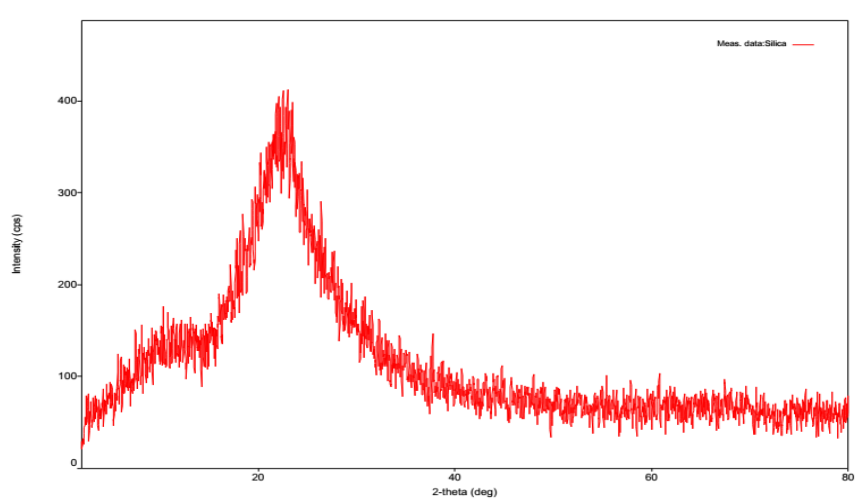

(A)

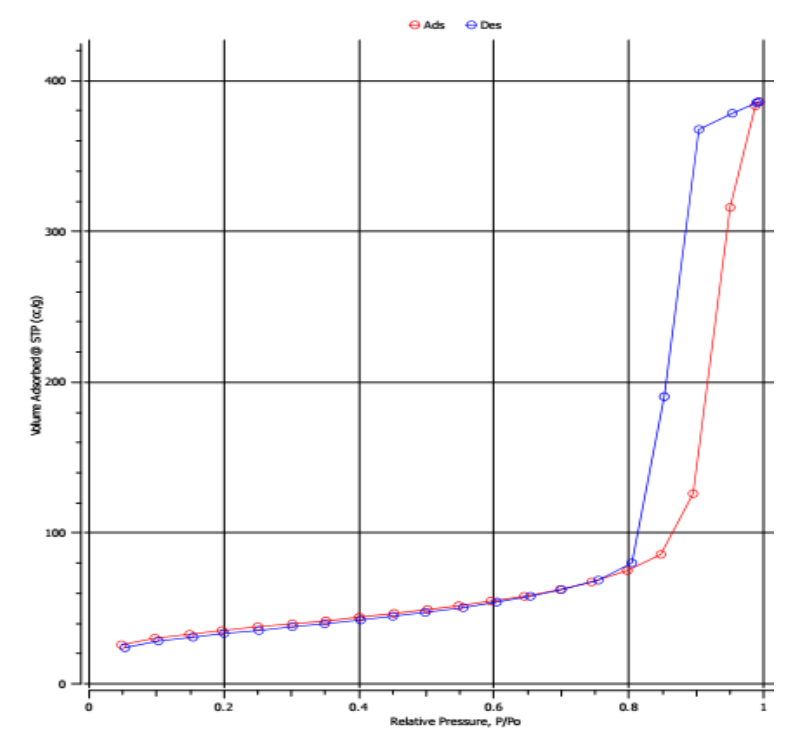

(C)

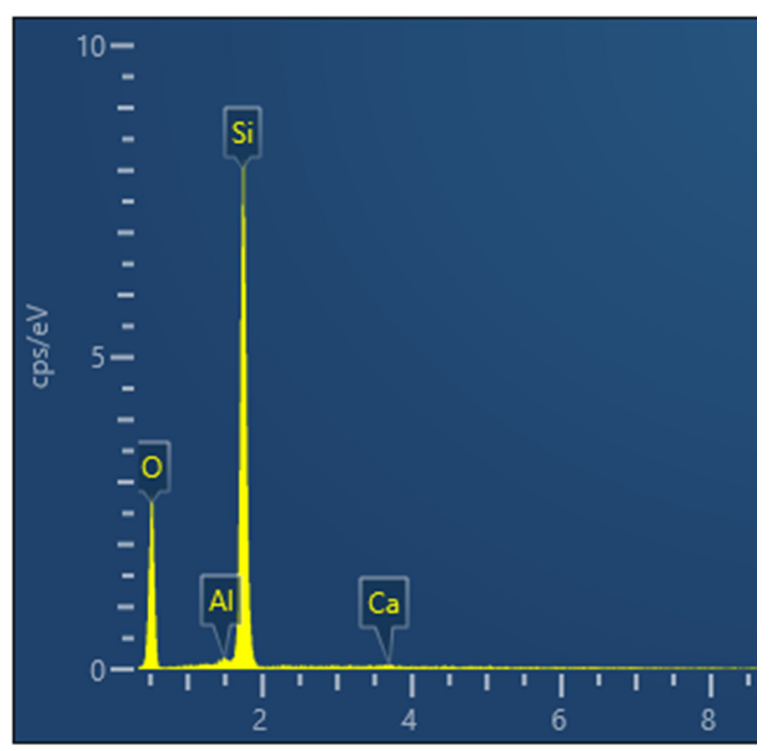

(E)

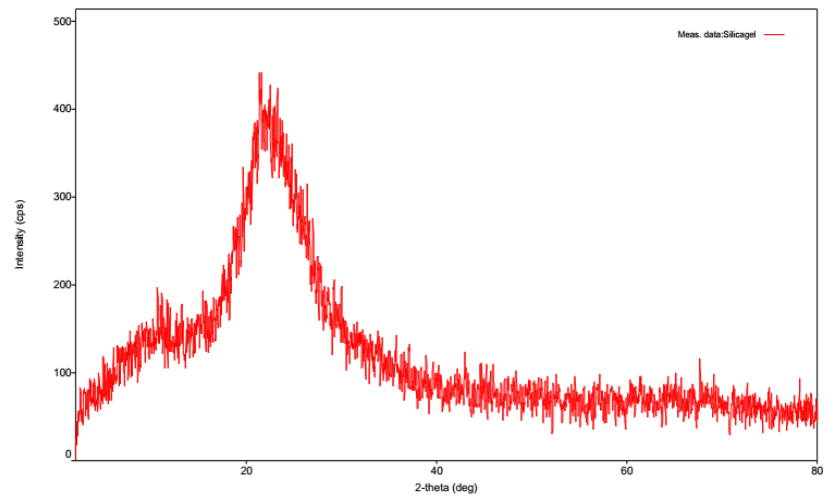

(B)

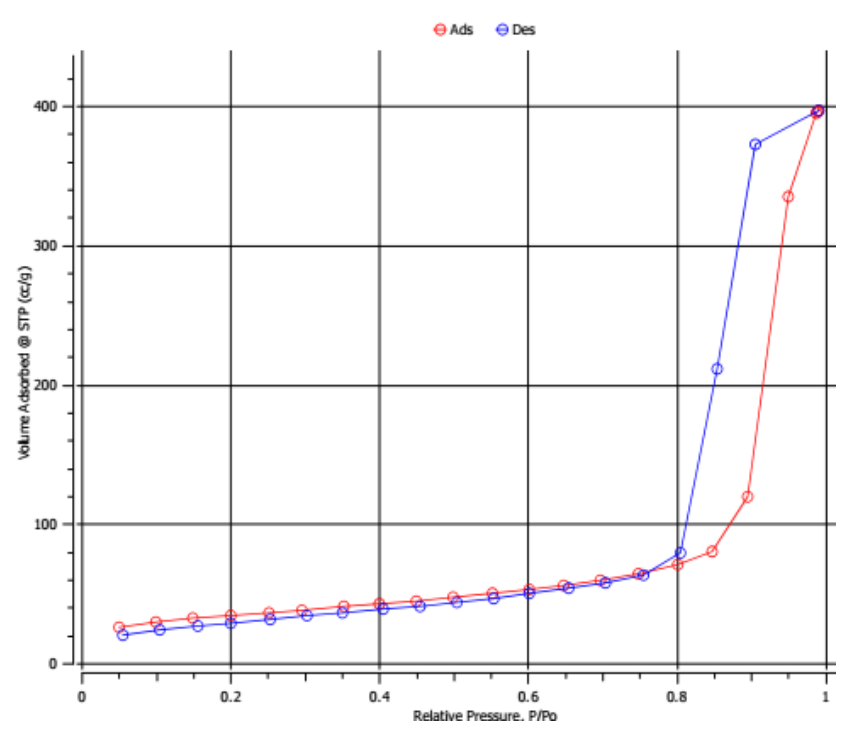

(D)

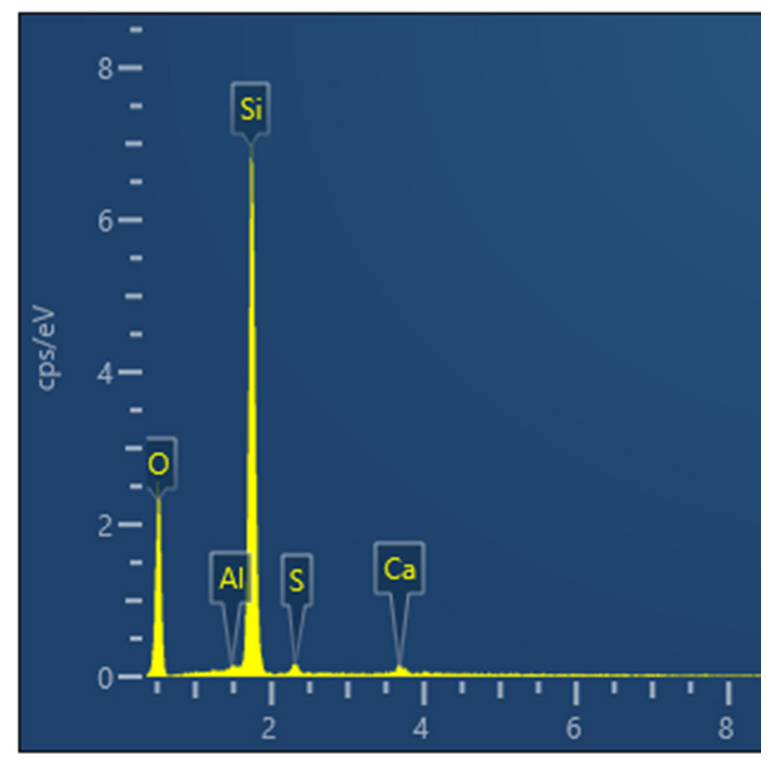

(F)

Figure 1. Characterization of silica and silica-gel. X-ray diffraction (XRD) patterns of silica (A) and silica-gel (B). Adsorption and desorption of $\mathrm{N}_{2}$ isotherms on silica (C) and silica-gel (D). The Energy Dispersive X-ray (EDX) of silica (E) and silica-gel (F). 
Anionic azo dye, new coccine (NCC), with purity higher than $85 \%$, from Tokyo Chemical Industry (Japan) was used as an adsorbate in dye adsorption. We used a strong polycation purchased from Sigam, poly-diallyl-dimethylammonium chloride (PDADMAC) $20 \mathrm{wt} . \%$ in $\mathrm{H}_{2} \mathrm{O}$ with a molecular weight of $400-500 \mathrm{~kg} \cdot \mathrm{mol}^{-1}$. The chemical structures of NCC and PDADMAC are indicated in Figure 2. The $\mathrm{pH}$ and ionic strength were adjusted by $\mathrm{KCl}, \mathrm{HCl}$, and $\mathrm{KOH}$. The solution $\mathrm{pH}$ was monitored by a $\mathrm{HI} 2215 \mathrm{pH}$ meter (Hanna, Woonsocket, RI, USA). All chemicals used in the present study are analytical reagents (Merck, Germany). The ultra-pure water was produced from a Thermo Scientific Barnstead MicroPure with resistivity of $18.2 \mathrm{M} \Omega . \mathrm{cm}$.<smiles></smiles>

(A)

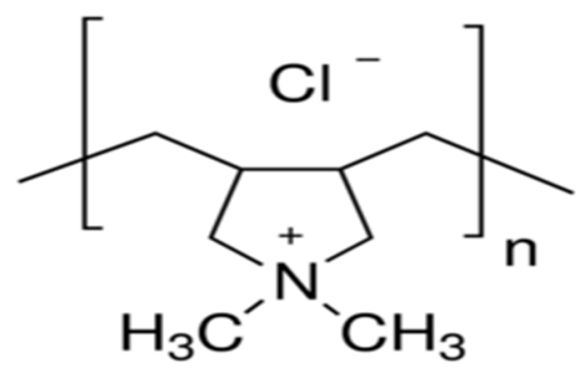

(B)

Figure 2. Chemical structures of anionic dye new coccine, NCC (A) and poly-diallyl-dimethylammonium chloride (PDADMAC) (B).

\subsection{Adsorption Study}

Adsorption studies were conducted by batch experiments in $10 \mathrm{~mL}$ fancol tubes at room temperature of $22 \pm 2{ }^{\circ} \mathrm{C}$, controlled by an air conditioner. To carry out adsorption experiments, the silica and silica-gel were mixed with various initial concentrations of PDADMAC under different ionic strengths. For NCC adsorption isotherms, concentrations from 20 to $1500 \mathrm{mg} \cdot \mathrm{L}^{-1}$ were desired and $\mathrm{pH}$ was adjusted to original value. The equilibrium time in dye adsorption was achieved after $60 \mathrm{~min}$. The adsorption amounts of PDADMAC ( $\left.\Gamma_{\text {PDADMAC }}\right)$ onto silica and silica-gel were determined by the differences between PDADMAC concentrations before and after adsorption monitored by total organic carbon analyzer (TOC- $\left.\mathrm{V}_{\mathrm{CSN}}\right)$. The adsorption capacities of NCC onto PDADMAC modified silica (PMS) and PDADMAC modified silica-gel (PMSG) were determined by the different concentrations of NCC solutions before adsorption and after equilibrium process by spectroscopic method.

The removal efficiency (\%R) of NCC was calculated by using Equation (1).

$$
\text { Removal }(\% \mathrm{R})=\frac{C_{i}-C_{e}}{C_{i}} \times 100 \%
$$


The adsorption isotherms of PDADMAC onto silica and silica-gel were fitted by the two-step model with general isotherm equation [39]:

$$
\Gamma=\frac{\Gamma_{\infty} \mathrm{k}_{1} \mathrm{C}\left(\frac{1}{\mathrm{n}}+\mathrm{k}_{2} \mathrm{C}^{\mathrm{n}-1}\right)}{1+\mathrm{k}_{1} \mathrm{C}\left(1+\mathrm{k}_{2} \mathrm{C}^{\mathrm{n}-1}\right)}
$$

where $\Gamma\left(\mathrm{mg} \cdot \mathrm{g}^{-1}\right)$ and $\Gamma_{\infty}\left(\mathrm{mg} \cdot \mathrm{g}^{-1}\right)$ are the adsorbed capacity and the maximum adsorption capacity of NCC, respectively, while $\mathrm{k}_{1}\left(\mathrm{~g} \cdot \mathrm{mg}^{-1}\right)$ and $\mathrm{k}_{2}\left(\mathrm{~g} \cdot \mathrm{mg}^{-1}\right)^{n-1}$ are equilibrium constants for first layer of adsorption, respectively; multilayer clusters of polymer molecules are denoted by $n$.

Adsorption of NCC onto PMS and PMSG were fitted by Langmuir and Freundlich models. The equation described by the Langmuir model is [40]:

$$
\frac{C_{e}}{q_{e}}=\frac{C_{e}}{q_{\max }}+\frac{1}{q_{\max } K_{L}}
$$

where $C_{e}\left(\mathrm{mg} \cdot \mathrm{L}^{-1}\right)$ is the NCC equilibrium concentrations, $q_{e}\left(\mathrm{mg} \cdot \mathrm{g}^{-1}\right)$ is the NCC adsorption capacity at equilibrium time, $q_{\max }\left(\mathrm{mg} \cdot \mathrm{g}^{-1}\right)$ is the maximum NCC adsorption capacity and $K_{L}\left(\mathrm{~L} \cdot \mathrm{g}^{-1}\right)$ is the Langmuir constant.

T Freundlich model with equation [41] is given below:

$$
\mathrm{Lnq}_{\mathrm{e}}=\mathrm{LnK}_{\mathrm{F}}+\frac{1}{n} \mathrm{LnC}_{\mathrm{e}}
$$

where $K_{F}\left(m g^{n-1} L^{n} \cdot g^{-1}\right)$ is the Freundlich constant while $n^{-1}$ is the adsorption intensity.

\subsection{Spectroscopic Method}

All concentrations of NCC were quantified by spectroscopic method using an UV-Vis double-beam spectrophotometer (UV-1650 PC, Shimadzu, Japan) at a wavelength of $505 \mathrm{~nm}$. The standard calibration curves at different conditions of $\mathrm{pH}$ and $\mathrm{NaCl}$ concentrations were daily conducted with a correlation coefficient of at least 0.999 . All samples were directly measured, or measured after appropriate dilution by standard calibration curves.

The FT-IR spectra were conducted on JASCO, Japan (FT-IR, 4600 type A) using deuterated triglycine sulfate (DTGS) detector with a resolution of $4 \mathrm{~cm}^{-1}$. All solid samples were measured using $\mathrm{KBr}$ pellets. The wavenumber was recorded from 400 to $4000 \mathrm{~cm}^{-1}$.

\section{Results and Discussion}

\subsection{Adsorption of PDADMAC onto Silica and Silicagel}

Adsorption isotherms of PDADMAC onto silica and silica-gel at three $\mathrm{KCl}$ concentration ( $\mathrm{pH} 10)$ are indicated in Figure 3. 


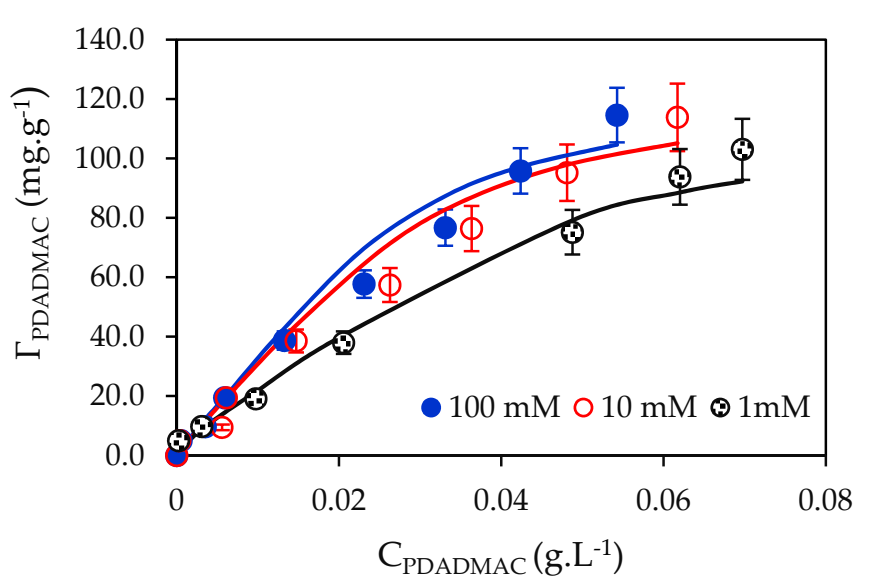

(A)

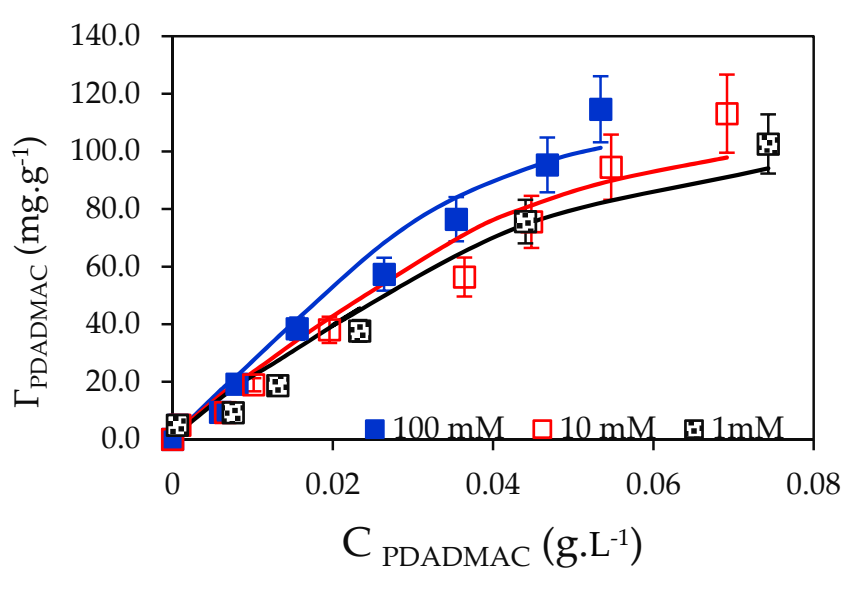

(B)

Figure 3. Adsorption isotherms of PDADMAC onto silica (A) and silica-gel (B) at three $\mathrm{KCl}$ concentrations. Points are experimental data, solid lines are the results calculated from the two-step model.

Figure 3 shows that adsorption increased with increasing $\mathrm{KCl}$ concentration while an increase in the number of cations $\mathrm{K}^{+}$induces a decrease in the electrostatic attraction between silica, silica-gel and PDADMAC. The electrostatic attraction between the cationic $\mathrm{PDADMA}^{+}$and negatively charged silica and silica-gel surfaces is decreased with an increase of $\mathrm{KCl}$ concentration [42]. Although the increases in PDADMAC adsorption onto both silica and silica-gel are not very high at 10 and $100 \mathrm{mM}$, the increase in adsorption capacity is clearly observed at $1 \mathrm{mM}$. This indicates that the non-electrostatic interaction plays an important role. Non-electrostatic interaction, which may be hydrophobic, lateral or hydrogen bonding, could influence the adsorption [43]. The adsorption of PDADMAC in our cases is similar to the adsorption of polyanion PSS onto alumina surface [44]. Adsorption of polyelectrolytes can eliminate the counter ions in aqueous solution, therefore adsorption may change the entropy [31,45].

Figure 3 also shows that the two-step model using the parameters in Table 1 can reasonably represent PDADMAC adsorption onto both silica and silica-gel at three ionic strengths of 1,10 and $100 \mathrm{mM}$. Interestingly, the value of $k_{1}$ did not change for all cases while the values of $k_{2}$ increased with increasing $\mathrm{KCl}$ concentration. The different in maximum adsorption capacities for all case were insignificant, demonstrating that PDADMAC attached easily to the adsorbent with negatively charged surfaces. It also indicates that many loops and tails of PDADMAC occurred on silica and silica-gel surfaces. In addition, the values of $n$ were the same with adsorbent, suggesting that PDADMAC adsorption with multilayer formation had taken place. In order to achieve a high positively charged surface, the initial PDADMAC concentration of $1 \mathrm{mg} \cdot \mathrm{mL}^{-1}$ was selected to modify silica and silica-gel surfaces.

Table 1. Fit parameters for polydiallyldimethylammonium chloride (PDADMAC) adsorption onto silica and silica-gel.

\begin{tabular}{|c|c|c|c|c|c|}
\hline Adsorbent & $\mathrm{C}_{\mathrm{KCl}}(\mathrm{mM})$ & $\Gamma_{\infty}\left(\mathrm{mg} \cdot \mathrm{g}^{-1}\right)$ & $\begin{array}{c}k_{1} \times 10^{2} \\
\left(\mathrm{~g} \cdot \mathrm{mg}^{-1}\right)\end{array}$ & $\begin{array}{c}k_{2} \times 10^{2} \\
\left(\mathrm{~g} \cdot \mathrm{mg}^{-1}\right)^{\mathrm{n}-1}\end{array}$ & $n$ \\
\hline \multirow{3}{*}{ Silica } & 1 & 110 & 1.0 & 8.0 & 2.9 \\
\hline & 10 & 120 & 1.0 & 8.0 & 2.8 \\
\hline & 100 & 120 & 1.0 & 10 & 2.8 \\
\hline \multirow{3}{*}{ Silica-gel } & 1 & 110 & 1.0 & 8.0 & 3.0 \\
\hline & 10 & 115 & 1.0 & 9.0 & 3.0 \\
\hline & 100 & 120 & 1.0 & 15 & 3.0 \\
\hline
\end{tabular}




\subsection{Comparison of NCC Removal Using Silica and Silica-Gel without and with PDADMAC Modification}

After surface modification of silica and silica-gel with PDADMAC, the surfaces of both silica and silica-gel become highly positive charged, which can enhance the adsorption of anionic azo dye NCC [16].

Figure 4 shows that the NCC removal using silica and silica-gel without PDADMAC modification is extremely low at all $\mathrm{pH}$ in a range of 3-10 because the surface charge silica and silica-gel are completely negative at all $\mathrm{pH}$ values. The interaction between negatively charged NCC species with both silica and silica-gel surfaces was negligible due to the strong electrical repulsion forces. Nevertheless, the removal of NCC using silica and silica-gel increased dramatically to more than $93 \%$ after surface modification by PDADMAC (namely, PMS and PMSG adsorbents). The effect of $\mathrm{pH}$ for NCC removal using PMSG was more clear than that for PMS in the pH range 2-8. From $\mathrm{pH} 8-10$, similar trends in significant decrease of NCC removal were observed for both PMS and PMSG because of the dissolution of silica and silica-gel [46]. The maximum NCC removal using both PMS and PMSG was reached at pH 6. Few studies have investigated NCC removal through the adsorption technique using other adsorbents. NCC removal using both PMS and PMSG has not been reported. NCC removal efficiencies using PMS and PMSG are much higher than that using silica and silica-gel without PDADMAC modification, so that further studies should only focus on PMS and PMSG adsorbents.

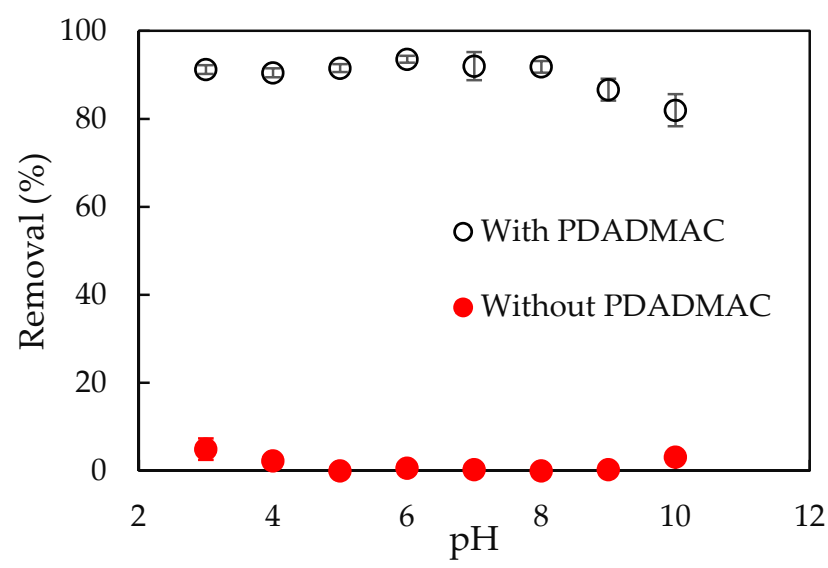

(A)

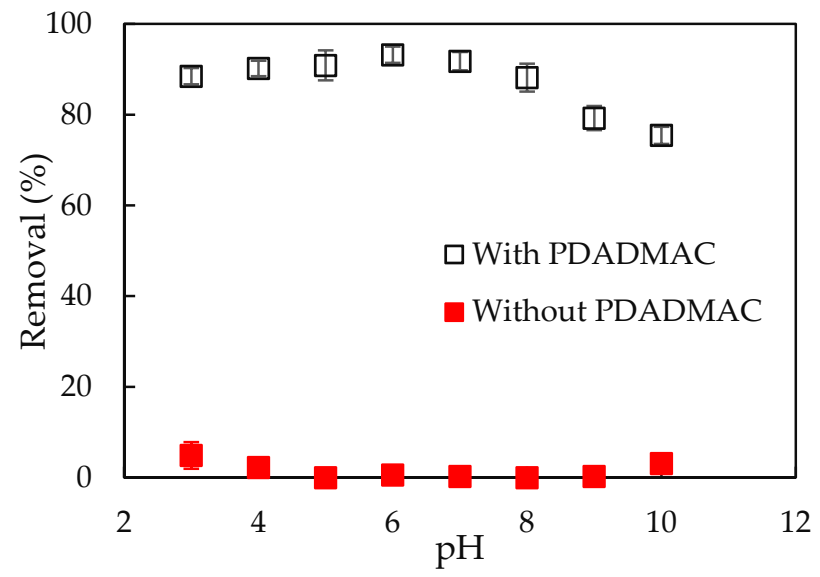

(B)

Figure 4. Comparison of NCC removal using silica (A) and silica-gel (B) with and without PDADMAC modification. $\left(\mathrm{C}_{\mathrm{NCC}}\right.$ $20 \mathrm{mg} \cdot \mathrm{L}^{-1}$, adsorption time $30 \mathrm{~min}$, adsorbent dosage $10 \mathrm{mg} \cdot \mathrm{mL}^{-1}$ ). Error bars show standard deviations of three replicates.

The optimum conditions for NCC removal using PMS and PMSG are indicated in detail below.

\subsection{Adsorptive Removal of NCC Using PMS and PMSG}

\subsubsection{Effect of Contact Time}

Contact time strongly induces the adsorption equilibria. The effect of contact time on the adsorptive removal of NCC using PMS and PMSG is presented in Figure 5. As can be seen, the NCC removal increased very quickly with an increase of contact time from $10 \mathrm{~min}$ to $60 \mathrm{~min}$ for both PMS and PMSG. After $60 \mathrm{~min}$, the NCC removal did not change significantly. The equilibration time of NCC onto PMS and PMSG in our case is similar to NCC adsorption on sludge particulate [37]. However, the NCC removal efficiencies in this case are much higher than in the previous study. Therefore, an equilibration time of $30 \mathrm{~min}$ was chosen for NCC removal using PMS and PMSG. 


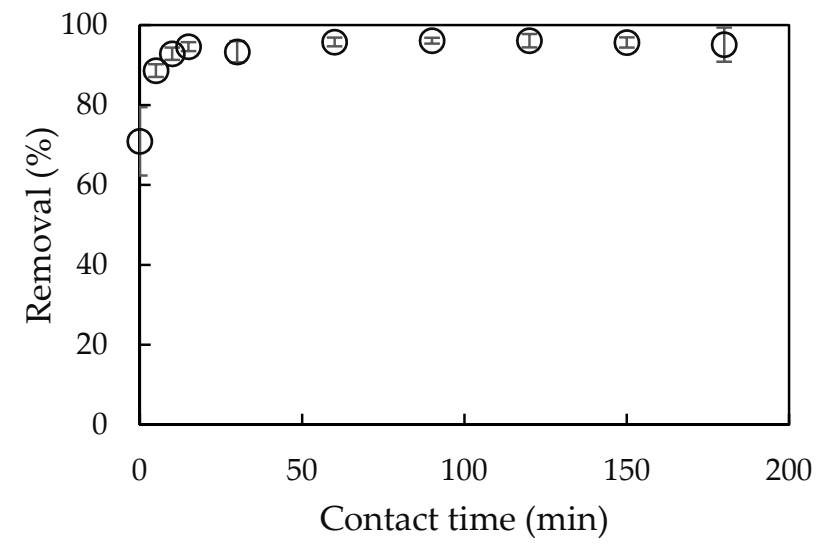

(A)

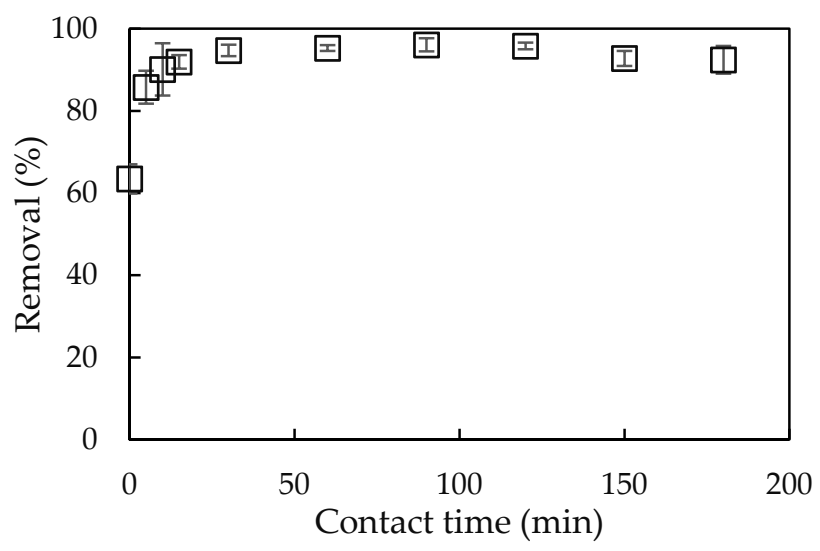

(B)

Figure 5. Effect of contact time on NCC removal using PMS (A) and PMSG (B). ( $\mathrm{C}_{\mathrm{NCC}} 20 \mathrm{mg} / \mathrm{L}$, pH 6, adsorbent dosage $\left.10 \mathrm{mg} \cdot \mathrm{mL}^{-1}\right)$. Error bars show the standard deviations of triplicates.

\subsubsection{Effect of Adsorbent Dosage}

The adsorbent dosage inducing the total surface area of adsorbent and the net surface charge $[2,17]$ highly influence to adsorption process.

Figure 6 indicates that the removal of NCC using PMS and PMSG dramatically increased along with increasing adsorbent dosage in the range of $1-10 \mathrm{mg} \cdot \mathrm{mL}^{-1}$ for PMS and from 1 to $20 \mathrm{mg} \cdot \mathrm{mL}^{-1}$ for PMSG. This implies that NCC removal using PMS required less adsorbent than PMSG due to the surface activity of silica after treatment at high temperature. The increase in available binding sites and net charge density for the adsorption, with an increase in adsorbent dosage, enhanced the increase in NCC removal [47]. However, an increase in adsorbent dosage did not affect the removal due to the maximum binding sites and surface charge density. The optimum adsorbent dosages for NCC removal using PMS and PMSG were found to be 10 and $20 \mathrm{mg} \cdot \mathrm{mL}^{-1}$, respectively.

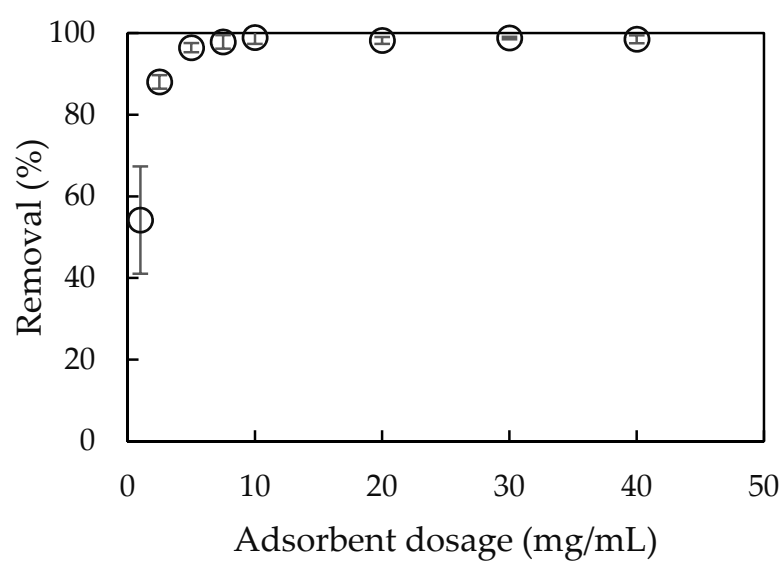

(A)

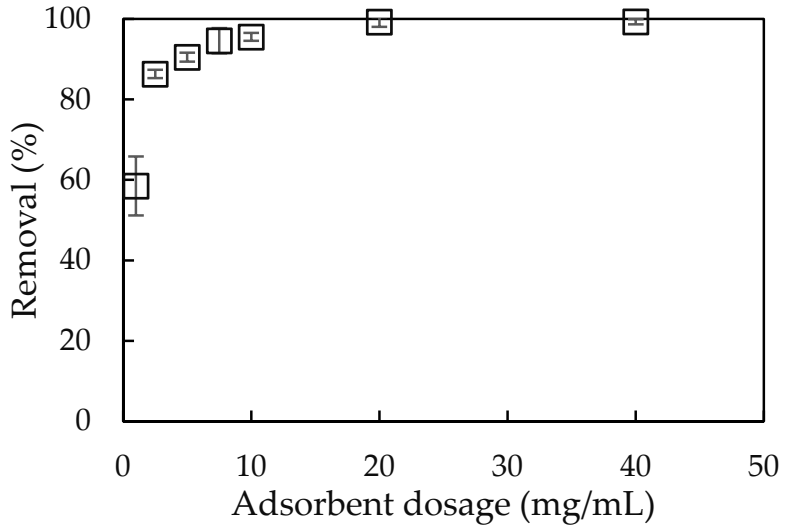

(B)

Figure 6. Effect of adsorbent dosage on NCC removal using PMS (A) and PMSG (B). $\left(\mathrm{C}_{\mathrm{NCC}} 20 \mathrm{mg} \cdot \mathrm{L}^{-1}\right.$, pH 6, contact time $30 \mathrm{~min})$. Error bars show the standard deviations of triplicates.

\subsection{Adsorption Isotherms of NCC onto PMS and PMSG}

The effect of ionic strength on NCC adsorption onto oppositely charged PMS and PMSG surfaces is clearly represented by adsorption isotherms at three salt concentrations at $\mathrm{pH}$ 6. We used two isothermal models to fit adsorption isotherms of NCC onto PMS 
and PMSG. Table 2 shows the parameters of NCC adsorption isotherms onto PMS and PMSG fitted by Langmuir and Freundlich models at different $\mathrm{KCl}$ concentrations from 1 to $100 \mathrm{mM}$.

Table 2. The parameters for NCC adsorption isotherms onto PDADMAC modified silica (PMS) and PDADMAC modified silica-gel (PMSG) at different $\mathrm{KCl}$ concentrations by Langmuir and Freundlich models.

\begin{tabular}{|c|c|c|c|c|c|}
\hline \multirow{2}{*}{ Adsorbent } & \multirow{2}{*}{ Model } & \multirow{2}{*}{ Parameter } & \multicolumn{3}{|c|}{$\mathrm{KCl}$ Concentration (mM) } \\
\hline & & & 1 & 10 & 100 \\
\hline \multirow{6}{*}{ PMS } & \multirow{3}{*}{ Langmuir } & $\underset{\left(\mathrm{mg} \cdot \mathrm{g}^{-1}\right)}{\mathrm{q} \max }$ & 58.08 & 44.64 & 44.92 \\
\hline & & $\mathrm{K}_{\mathrm{L}}\left(\mathrm{L} \cdot \mathrm{g}^{-1}\right)$ & 0.029 & 0.099 & 0.065 \\
\hline & & $\mathrm{R}^{2}$ & 0.9593 & 0.9985 & 0.9989 \\
\hline & \multirow{3}{*}{ Freundlich } & $\mathrm{K}_{\mathrm{F}}$ & 6.092 & 7.148 & 6.833 \\
\hline & & $n$ & 2.741 & 3.317 & 3.160 \\
\hline & & $\mathrm{R}^{2}$ & 0.6165 & 0.5809 & 0.7455 \\
\hline \multirow{6}{*}{ PMSG } & \multirow{3}{*}{ Langmuir } & $\underset{\left(\mathrm{mg} \cdot \mathrm{g}^{-1}\right)}{\mathrm{q} \max }$ & 64.12 & 55.09 & 52.63 \\
\hline & & $\mathrm{K}_{\mathrm{L}}\left(\mathrm{L} \cdot \mathrm{g}^{-1}\right)$ & 0.022 & 0.046 & 0.044 \\
\hline & & $\mathrm{R}^{2}$ & 0.9976 & 0.9980 & 0.9814 \\
\hline & \multirow{3}{*}{ Freundlich } & $\mathrm{K}_{\mathrm{F}}$ & 3.282 & 5.879 & 7.804 \\
\hline & & $n$ & 2.021 & 2.615 & 3.162 \\
\hline & & $\mathrm{R}^{2}$ & 0.8201 & 0.6063 & 0.7263 \\
\hline
\end{tabular}

As can be seen in Table 2, NCC adsorption capacities decreased sharply when increasing $\mathrm{KCl}$ concentration from 1 to $10 \mathrm{mM}$ for both PMS and PMSG, while they changed slightly from 10 to $100 \mathrm{mM}$. Adsorption of NCC on PMS and PMSG is controlled by both electrostatic and non-electrostatic interaction, but the electrostatic interaction is dominant. Maximum adsorption capacity using PMSG is always higher than that using PMS at different $\mathrm{KCl}$ concentrations, indicating that PMSG is better than PMS in terms of NCC removal. The Langmuir model achieved better results compared to Freundlich. This can be explained by the fact that anionic NC species may occur on the monolayer on both PMS and PMSG surfaces, although the Langmuir isotherm is based on physical adsorption [35]. In our cases, NCC adsorption onto PMS and PMSG was favored in chemical adsorption due to the presence of chemical bonding.

\subsection{Adsorption Mechanisms of NCC onto PMS and PMSG}

We evaluated the change in surface functional group by Fourier transform infrared spectroscopy (FT-IR) in combination with adsorption isotherms to suggest adsorption of NC onto PMS and PMSG. The FT-IR spectra of silica and silica-gel with and without PDADMAC modification and after NCC adsorption are shown in Figure 7. 


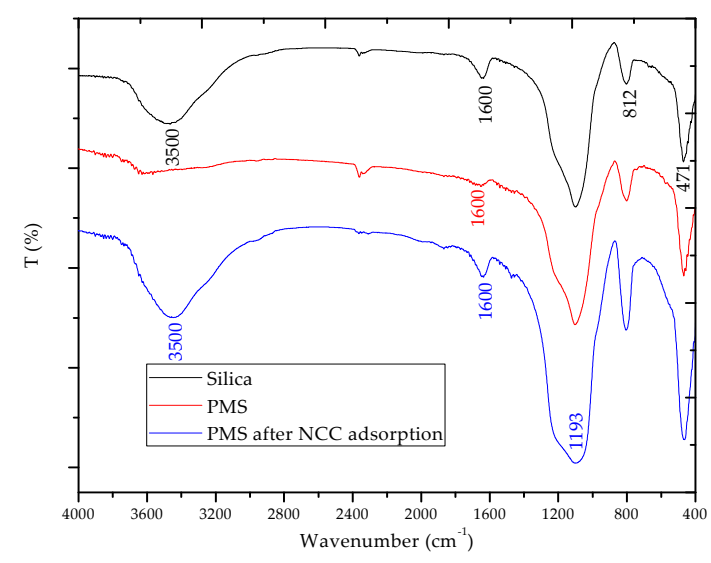

(A)

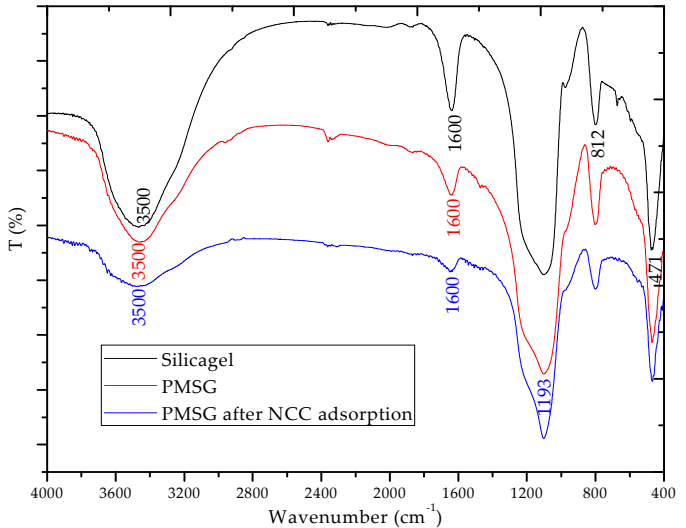

(B)

Figure 7. The FT-IR spectra of silica, PDADMAC modified silica (PMS) and PMS after NCC adsorption (A) and silica-gel, PMSG, PMSG after NCC adsorption (B).

Figure 7 shows that silica and silica-gel after PDADMAC adsorption have similar specific peaks, except for the vibration of -OH at a wavelength of about 3500 and $1600 \mathrm{~cm}^{-1}$. This - $\mathrm{OH}$ peak appeared clearly for silica-gel because the hydroxyl group is eliminated at high temperature in the case of silica. The peaks of the -NH vibration of ammonium cations in PDADMAC at $1473.62 \mathrm{~cm}^{-1}$ disappeared after adsorption onto both silica and silica-gel [48]. The intensity peak at $1600 \mathrm{~cm}^{-1}$ for silica-gel decreased while this peak disappeared after PDADMAC modification. This suggests that hydrogen bonding may induce the adsorption of polycation onto silica and silica-gel. In addition, the peaks of 812 $\mathrm{cm}^{-1}$ of symmetric Si-O shifted to a shorter wavenumber while bending vibration assigned at about $471 \mathrm{~cm}^{-1}$ did not change after PDADMAC modification. These results indicate that PDADMAC adsorption on silica and silica-gel forms PMS and PMSG, respectively by both electrostatic and non-electrostatic interactions.

Figure 7 also shows that after NCC adsorption, the FT-IR spectra of PMS and PMSG are similar. The spectra of NC powder (data not shown) revealed that the bands at 1423, 1491,1570 and $1632 \mathrm{~cm}^{-1}$ were assigned different olefin bonding of naphthalene rings or phenyl ring vibration with stretching of the $\mathrm{C}=\mathrm{N}$ group, that corresponded to active groups of azo dye. These bands agree well with the spectra of NCC powder [49]. The peak at $1600 \mathrm{~cm}^{-1}$ assigned for -OH vibration appeared again for PMS, but its intensity still decreased for PMSG, while this peak disappeared after PDADMAC modification. We also found that the strong bands at 1193 and $1047 \mathrm{~cm}^{-1}$ assigned for the vibrations of the sulfonic group [32,50] of NCC disappeared after adsorption onto PMS and PMSG. The results indicate NCC adsorption via two oxygen atoms of the sulfonic group of the azo dye $[32,50]$ and $-\mathrm{NH}$ groups occurring on PMS and PMSG. These are in good agreement with adsorption isotherms in which ionic strength plays a crude role due to the presence of electrostatic interaction. Based on adsorption isotherms and the change in vibration surface active groups by FT-IR, we suggest that NCC adsorption Ponto PMS and PMSG is mainly by electrostatic attraction between anionic species of NCC and positively charged PMS and PMSG surfaces.

\subsection{Reusability of PMS and PMSG}

To demonstrate the performance of adsorbents, the regeneration of adsorbent is needed to evaluate the reusability and stability of PMS and PMSG [34]. The regeneration of both PMS and PMSG were conducted using $4 \mathrm{M} \mathrm{HCl}$. The reuse experiments were conducted in triplicate. 
Figure 8 shows the NCC removal using PMS and after five cycles. Although the NCC removal was slightly reduced, NCC removal efficiencies were greater than $87 \%$ after five cycles when using PMS and PMSG. This implies that PMS and PMSG are reusable adsorbents with high performance for NCC removal. These materials may further apply for removal not only of dye, but also of other organic pollutants [51] with negative charges.

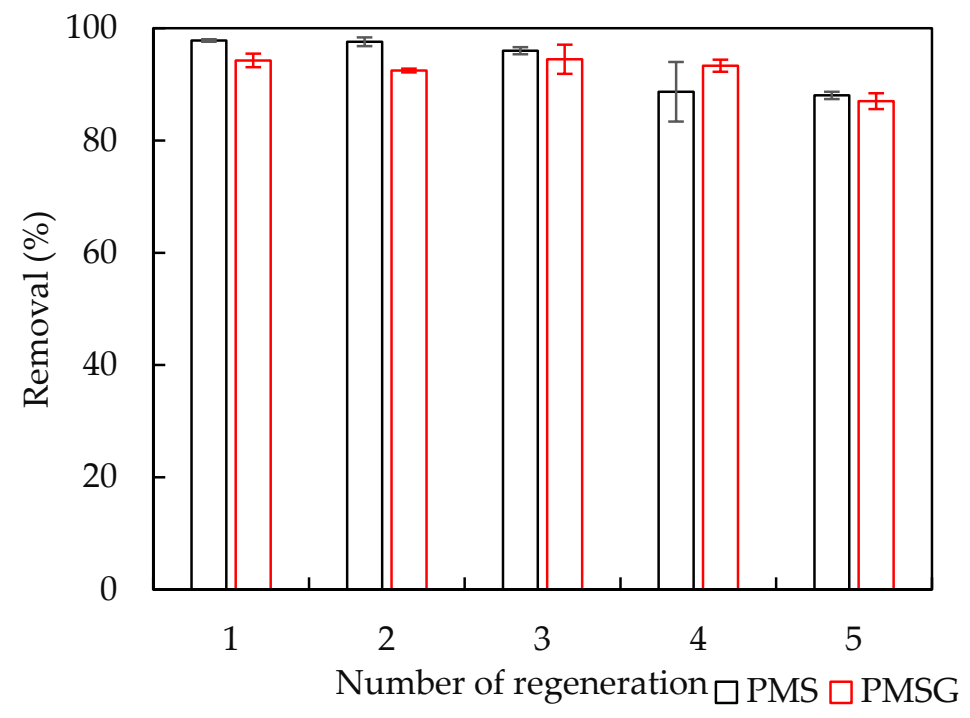

Figure 8. Removal of NCC using PMS and PMSG after five regenerations. Error bars show standard deviations of three replicates.

\section{Conclusions}

We have investigated the adsorption of anionic azo dye, NCC, onto silica and silicagel after pre-adsorption of polycation PDADMAC. The two-step model was successfully applied to represent the experimental results of adsorption isotherms of PDADMAC onto silica and silica-gel. NCC removal using silica and silica-gel was very low, but increased dramatically when using PMS and PMSG. The maximum NCC removal using PMS and PMSG was achieved at contact time $30 \mathrm{~min}, \mathrm{pH}$ 6. The optimum PMS and PMSG dosages for NCC removal were found to be 10 and $20 \mathrm{mg} \cdot \mathrm{mL}^{-1}$, respectively. Adsorption amounts of NCC decreased with increasing salt concentration, confirming that the NC adsorption onto PMS and PMSG is mainly induced by electrostatic attraction. After five regenerations, the NCC removal efficiencies using PMS and PMSG were greater than $87 \%$. The results of adsorption isotherms, the surface modifications by FTIR, suggested that adsorption of NCC is mainly controlled by electrostatic interaction based on the formation, between one sulfonic group on the naphthalene ring and cationic ammonium ion, of PMS and PMSG.

Author Contributions: Conceptualization, T.D.P. and T.D.N.; methodology, T.D.P. and T.D.N.; software, V.P.B. and T.N.P.; validation, V.P.B. and T.N.P.; formal analysis, V.P.B., T.N.P. and T.M.D.L.; investigation, V.P.B., K.T.N. and V.H.B.; resources, V.P.B. and K.T.N.; data curation, V.P.B., T.N.P. and T.M.D.L.; writing-original draft preparation, T.D.P., V.P.B. and T.D.N.; writing-review and editing, T.D.P. and T.D.N.; visualization, K.T.N. and V.H.B.; supervision, T.D.P. and T.D.N.; project administration, T.D.N.; funding acquisition, T.D.N. All authors have read and agreed to the published version of the manuscript.

Funding: This research is funded by the Vietnam National University, Hanoi (VNU) under project number QG.20.22.

Institutional Review Board Statement: Not applicable.

Informed Consent Statement: Not applicable.

Data Availability Statement: Not applicable. 
Acknowledgments: The authors would like to thank Associate Motoyoshi Kobayashi at University of Tsukuba for the specific chemicals support.

Conflicts of Interest: The authors declare no conflict of interest.

\section{References}

1. Adak, A.; Bandyopadhyay, M.; Pal, A. Removal of crystal violet dye from wastewater by surfactant-modified alumina. Sep. Purif. Technol. 2005, 44, 139-144. [CrossRef]

2. Ngo, T.M.V.; Nguyen, T.H.L.; Mai, X.T.; Pham, T.H.N.; Nguyen, T.T.T.; Pham, T.D. Adsorptive removal of cationic dyes using hybrid material-based polyelectrolyte modified laterite soil. J. Environ. Chem. Eng. 2021, 9, 105135. [CrossRef]

3. Forgacs, E.; Cserháti, T.; Oros, G. Removal of synthetic dyes from wastewaters: A review. Environ. Int. 2004, 30, 953-971. [CrossRef] [PubMed]

4. Gupta, V.K.; Suhas. Application of low-cost adsorbents for dye removal-A review. J. Environ. Manag. 2009, 90, 2313-2342. [CrossRef]

5. Dao, T.H.; Tran, T.T.; Nguyen, V.R.; Pham, T.N.M.; Vu, C.M.; Pham, T.D. Removal of antibiotic from aqueous solution using synthesized $\mathrm{TiO}_{2}$ nanoparticles: Characteristics and mechanisms. Environ. Earth Sci. 2018, 77, 359. [CrossRef]

6. Daneshvar, N.; Salari, D.; Khataee, A.R. Photocatalytic degradation of azo dye acid red 14 in water: Investigation of the effect of operational parameters. J. Photochem. Photobiol. A Chem. 2003, 157, 111-116. [CrossRef]

7. Nagaveni, K.; Sivalingam, G.; Hegde, M.S.; Madras, G. Solar photocatalytic degradation of dyes: High activity of combustion synthesized nano $\mathrm{TiO}_{2}$. Appl. Catal. B Environ. 2004, 48, 83-93. [CrossRef]

8. Cuiping, B.; Xianfeng, X.; Wenqi, G.; Dexin, F.; Mo, X.; Zhongxue, G.; Nian, X. Removal of rhodamine B by ozone-based advanced oxidation process. Desalination 2011, 278, 84-90. [CrossRef]

9. Pérez, M.; Torrades, F.; Domènech, X.; Peral, J. Fenton and photo-Fenton oxidation of textile effluents. Water Res. 2002, 36, 2703-2710. [CrossRef]

10. Papić, S.; Koprivanac, N.; Lončarić Božić, A.; Meteš, A. Removal of some reactive dyes from synthetic wastewater by combined Al(III) coagulation/carbon adsorption process. Dye. Pigment. 2004, 62, 291-298. [CrossRef]

11. Ledakowicz, S.; Solecka, M.; Zylla, R. Biodegradation, decolourisation and detoxification of textile wastewater enhanced by advanced oxidation processes. J. Biotechnol. 2001, 89, 175-184. [CrossRef]

12. Chu, T.P.M.; Nguyen, N.T.; Vu, T.L.; Dao, T.H.; Dinh, L.C.; Nguyen, H.L.; Hoang, T.H.; Le, T.S.; Pham, T.D. Synthesis, Characterization, and Modification of Alumina Nanoparticles for Cationic Dye Removal. Materials 2019, 12, 450. [CrossRef]

13. Pham, T.D.; Kobayashi, M.; Adachi, Y. Adsorption characteristics of anionic azo dye onto large $\alpha$-alumina beads. Colloid Polym. Sci. 2015, 293, 1877-1886. [CrossRef]

14. Pham, T.D.; Pham, T.T.; Phan, M.N.; Ngo, T.M.V.; Dang, V.D.; Vu, C.M. Adsorption characteristics of anionic surfactant onto laterite soil with differently charged surfaces and application for cationic dye removal. J. Mol. Liq. 2020, 301, 112456. [CrossRef]

15. Yen Doan, T.H.; Minh Chu, T.P.; Dinh, T.D.; Nguyen, T.H.; Tu Vo, T.C.; Nguyen, N.M.; Nguyen, B.H.; Nguyen, T.A.; Pham, T.D. Adsorptive Removal of Rhodamine B Using Novel Adsorbent-Based Surfactant-Modified Alpha Alumina Nanoparticles. J. Anal. Methods Chem. 2020, 2020, 6676320. [CrossRef] [PubMed]

16. Pham, T.D.; Bui, T.T.; Trang Truong, T.T.; Hoang, T.H.; Le, T.S.; Duong, V.D.; Yamaguchi, A.; Kobayashi, M.; Adachi, Y. Adsorption characteristics of beta-lactam cefixime onto nanosilica fabricated from rice HUSK with surface modification by polyelectrolyte. $J$. Mol. Liq. 2020, 298, 111981. [CrossRef]

17. Pham, T.-D.; Le, T.-M.-A.; Pham, T.-M.-Q.; Dang, V.-H.; Vu, K.-L.; Tran, T.-K.; Hoang, T.-H. Synthesis and Characterization of Novel Hybridized $\mathrm{CeO}_{2} @ \mathrm{SiO}_{2}$ Nanoparticles Based on Rice Husk and Their Application in Antibiotic Removal. Langmuir 2021, 37, 2963-2973. [CrossRef] [PubMed]

18. Cseri, L.; Topuz, F.; Abdulhamid, M.A.; Alammar, A.; Budd, P.M.; Szekely, G. Electrospun Adsorptive Nanofibrous Membranes from Ion Exchange Polymers to Snare Textile Dyes from Wastewater. Adv. Mater. Technol. 2021, 2000955. [CrossRef]

19. Wang, Q.; Zhang, L.; Guo, Y.; Shen, M.; Wang, M.; Li, B.; Shi, J. Multifunctional 2D porous g- $\mathrm{C}_{3} \mathrm{~N}_{4}$ nanosheets hybridized with 3D hierarchical $\mathrm{TiO}_{2}$ microflowers for selective dye adsorption, antibiotic degradation and $\mathrm{CO}_{2}$ reduction. Chem. Eng. J. 2020, 396, 125347. [CrossRef]

20. Wang, B.; Chen, P.-Y.; Zhao, R.-X.; Zhang, L.; Chen, Y.; Yu, L.-P. Carbon-dot modified polyacrylonitrile fibers: Recyclable materials capable of selectively and reversibly adsorbing small-sized anionic dyes. Chem. Eng. J. 2020, 391, 123484. [CrossRef]

21. Nguyen, N.T.; Dao, T.H.; Truong, T.T.; Nguyen, T.M.T.; Pham, T.D. Adsorption characteristic of ciprofloxacin antibiotic onto synthesized alpha alumina nanoparticles with surface modification by polyanion. J. Mol. Liq. 2020, 309, 113150. [CrossRef]

22. Dao, T.-H.; Vu, T.-Q.-M.; Nguyen, N.-T.; Pham, T.-T.; Nguyen, T.-L.; Yusa, S.-I.; Pham, T.-D. Adsorption Characteristics of Synthesized Polyelectrolytes onto Alumina Nanoparticles and their Application in Antibiotic Removal. Langmuir 2020, 36, 13001-13011. [CrossRef] [PubMed]

23. Guzmán, E.; Ritacco, H.A.; Ortega, F.; Rubio, R.G. Growth of Polyelectrolyte Layers Formed by Poly(4-styrenesulfonate sodium salt) and Two Different Polycations: New Insights from Study of Adsorption Kinetics. J. Phys. Chem. C 2012, 116, 15474-15483. [CrossRef]

24. Chen, Z.; Zhou, L.; Zhang, F.; Yu, C.; Wei, Z. Multicarboxylic hyperbranched polyglycerol modified SBA-15 for the adsorption of cationic dyes and copper ions from aqueous media. Appl. Surf. Sci. 2012, 258, 5291-5298. [CrossRef] 
25. Harris, R.G.; Wells, J.D.; Johnson, B.B. Selective adsorption of dyes and other organic molecules to kaolinite and oxide surfaces. Colloids Surf. A Physicochem. Eng. Asp. 2001, 180, 131-140. [CrossRef]

26. Jain, V.K.; Mundhara, G.L.; Tiwari, J.S. Sorption-Desorption studies of anionic dyes on alumina pretreated with acids. Colloids Surf. 1988, 29, 373-389. [CrossRef]

27. Yahyaei, B.; Azizian, S. Rapid adsorption of anionic dyes by ordered nanoporous alumina. Chem. Eng. J. 2012, 209, 589-596. [CrossRef]

28. Mishael, Y.G.; Dubin, P.L. Uptake of Organic Pollutants by Silica-Polycation-Immobilized Micelles for Groundwater Remediation. Environ. Sci. Technol. 2005, 39, 8475-8480. [CrossRef] [PubMed]

29. Wang, Y.; Banziger, J.; Dubin, P.L.; Filippelli, G.; Nuraje, N. Adsorptive Partitioning of an Organic Compound onto PolyelectrolyteImmobilized Micelles on Porous Glass and Sand. Environ. Sci. Technol. 2001, 35, 2608-2611. [CrossRef]

30. Zadaka, D.; Mishael, Y.G.; Polubesova, T.; Serban, C.; Nir, S. Modified silicates and porous glass as adsorbents for removal of organic pollutants from water and comparison with activated carbons. Appl. Clay Sci. 2007, 36, 174-181. [CrossRef]

31. Guzman, E.; Ritacco, H.; Rubio, J.E.F.; Rubio, R.G.; Ortega, F. Salt-induced changes in the growth of polyelectrolyte layers of poly(diallyl-dimethylammonium chloride) and poly(4-styrene sulfonate of sodium). Soft Matter 2009, 5, 2130-2142. [CrossRef]

32. Bandara, J.; Mielczarski, J.A.; Kiwi, J. Molecular Mechanism of Surface Recognition. Azo Dyes Degradation on Fe, Ti, and Al Oxides through Metal Sulfonate Complexes. Langmuir 1999, 15, 7670-7679. [CrossRef]

33. Zuorro, A.; Lavecchia, R.; Monaco, M.M.; Iervolino, G.; Vaiano, V. Photocatalytic Degradation of Azo Dye Reactive Violet 5 on Fe-Doped Titania Catalysts under Visible Light Irradiation. Catalysts 2019, 9, 645. [CrossRef]

34. Zuorro, A.; Maffei, G.; Lavecchia, R. Kinetic modeling of azo dye adsorption on non-living cells of Nannochloropsis oceanica. J. Environ. Chem. Eng. 2017, 5, 4121-4127. [CrossRef]

35. Zuorro, A.; Santarelli, M.L.; Lavecchia, R. Tea Waste: A New Adsorbent for the Removal of Reactive Dyes from Textile Wastewater. Adv. Mater. Res. 2013, 803, 26-29. [CrossRef]

36. Fidaleo, M.; Lavecchia, R.; Petrucci, E.; Zuorro, A. Application of a novel definitive screening design to decolorization of an azo dye on boron-doped diamond electrodes. Int. J. Environ. Sci. Technol. 2016, 13, 835-842. [CrossRef]

37. Wang, J.; Huang, C.P.; Allen, H.E.; Cha, D.K.; Kim, D.-W. Adsorption Characteristics of Dye onto Sludge Particulates. J. Colloid Interface Sci. 1998, 208, 518-528. [CrossRef] [PubMed]

38. Pham, T.D.; Vu, C.M.; Choi, H.J. Enhanced fracture toughness and mechanical properties of epoxy resin with rice husk-based nano-silica. Polym. Sci. Ser. A 2017, 59, 437-444. [CrossRef]

39. Gu, T.; Zhu, B.-Y.; Rupprecht, H. Surfactant adsorption and surface micellization. In Advances in Colloid Structures; Springer: Berlin/Heidelberg, Germany, 1992; pp. 74-85.

40. Langmuir, I. The Adsorption of Gases on Plane Surfaces of Glass, Mica and Platinum. J. Am. Chem. Soc. 1918, 40, 1361-1403. [CrossRef]

41. Freundlich, H. Über die adsorption in Lösungen. Z. Phys. Chem. 1906, 57A, 385. [CrossRef]

42. Matsumoto, T.; Adachi, Y. Effect of Ionic Strength on the Initial Dynamics of Flocculation of Polystyrene Latex with Polyelectrolyte. J. Colloid Interface Sci. 1998, 204, 328-335. [CrossRef]

43. Mészáros, R.; Thompson, L.; Bos, M.; de Groot, P. Adsorption and Electrokinetic Properties of Polyethylenimine on Silica Surfaces. Langmuir 2002, 18, 6164-6169. [CrossRef]

44. Pham, T.D.; Kobayashi, M.; Adachi, Y. Adsorption of Polyanion onto Large Alpha Alumina Beads with Variably Charged Surface. Adv. Phys. Chem. 2014, 2014, 9. [CrossRef]

45. Guzmán, E.; Cavallo, J.A.; Chuliá-Jordán, R.; Gómez, C.; Strumia, M.C.; Ortega, F.; Rubio, R.G. pH-Induced Changes in the Fabrication of Multilayers of Poly (acrylic acid) and Chitosan: Fabrication, Properties, and Tests as a Drug Storage and Delivery System. Langmuir 2011, 27, 6836-6845. [CrossRef] [PubMed]

46. Zha, S.X.; Zhou, Y.; Jin, X.; Chen, Z. The removal of amoxicillin from wastewater using organobentonite. J. Environ. Manag. 2013, 129, 569-576. [CrossRef] [PubMed]

47. Mazloomi, F.; Jalali, M. Ammonium removal from aqueous solutions by natural Iranian zeolite in the presence of organic acids, cations and anions. J. Environ. Chem. Eng. 2016, 4, 1664-1673. [CrossRef]

48. Kochameshki, M.G.; Marjani, A.; Mahmoudian, M.; Farhadi, K. Grafting of diallyldimethylammonium chloride on graphene oxide by RAFT polymerization for modification of nanocomposite polysulfone membranes using in water treatment. Chem. Eng. J. 2017, 309 (Suppl. C), 206-221. [CrossRef]

49. Park, I.Y.; Kuroda, K.; Kato, C. Direct synthesis of intercalation compounds between a layered double hydroxide and an anionic dye. J. Chem. Soc. Dalton Trans. 1990, 3071-3074. [CrossRef]

50. Bourikas, K.; Stylidi, M.; Kondarides, D.I.; Verykios, X.E. Adsorption of Acid Orange 7 on the Surface of Titanium Dioxide. Langmuir 2005, 21, 9222-9230. [CrossRef]

51. Petrucci, E.; Di Palma, L.; Lavecchia, R.; Zuorro, A. Modeling and optimization of Reactive Green 19 oxidation on a BDD thin-film electrode. J. Taiwan Inst. Chem. Eng. 2015, 51, 152-158. [CrossRef] 